\title{
MACHINABILITY OF METALS, METHODS AND PRACTICAL APPLICATION
}

\author{
QEHAJA, N[exhat] E.; SALIHU, A[vdi] H[ajdin]; ZEQIRI, H[akif] M[ehmet]; \\ OSMANI, H[ysni] \& ZEQIRI, F[itim]
}

\begin{abstract}
Machinability is a fundamental technological feature of the machined metal and is an economic feature of the cutting operations. Machinability of metals and the tool cutting capacities are mutually related terms and are defined by the same methods. These terms express the extent of the ability of metal to be machined as well as the potential opportunities of the tool to accomplish specific tasks under set of specific conditions and to achieve satisfactory economic results. These are characterized by complexity, intricacy, relativity and randomness. They are evaluated according to their reliability, energy and cost indicators and are determined experimentally using the classical method and by numerous quick methods, which in genral are approximative. A new means of expression of practical application are the characteristic lines and the probability field.

Keywords: machinability, cutting ability, characteristics lines, probability field, normal and accelerated methods
\end{abstract}

\section{INTRODUCTION}

The term "machining" was originally used in 1920 in connection with the "tool life - cutting speed" dependence. Terms of similar meaning are "machining suitability" and "machining certainty". Unfortunately, these have never found theoretical or practical application, despite the obvious content they hold.

The term "machining by chip removal" holds an extremely complex meaning, adopted intuitively and most often, the meaning in theory or in practice is associated differently. It usually refers to the influence of or from machinability, rather than to machinability itself [3]. There are still no sufficiently precise and complete definitions of machinability with theoretical and practical focus. However, the general perception is that machinability is a fundamental, unique and comprehensive technological characteristic of metals and of the cutting process [2].

The research, management and improvement of machinability of metals have been the subject of many scholars from universities and of industry specialists from different countries. Since sixties of last century, the specialized group (group "C" with the International CIRP Organization [4]) has permanently considered, discussed and resolved issues to determine and study machinability. This study is important for the practical implementation of the efficient processing of metals.

\section{MACHINABILITY OF METALS}

Machinability of metals by chip removal consists of the characteristics, which indicate the possibility and ability of the metal to be processed when being cut. In some cases, machinability restricts productivity or makes it difficult to ensure the required accuracy and surface roughness of the machined surface [5]. One disadvantage of this definition is that it does not answer the question of how machinability can be determined, calculated or expressed. Therefore, the definition loses its technological meaning and practical relevance.

Machinability is not an abstract concept. It is a measure of qualitative (descriptive) or quantitative (numerical) evaluation of the metal cutting process in certain manufacturing equipment and technology. Machinability is the result of complex interactions of the treated metal and the cutting tool. It takes into account both the physical side of the cutting process and the peculiarities during the process of the operations. Therefore, it is seen as a prerequisite for obtaining effective machinability [7].

From the analysis of machinability, Andonov gives a more general definition [9]. "Machinability is the main technological characteristics of the processed metal and an economic characteristics of the process of cutting, which express the level of the ability of the metal to be treated with a cutting tool in a given situation, subject to certain technological conditions in achieving satisfactory final economic results." The degree of this ability is quantitatively assessed by one parameter or by several parameters. The economic performance is measured by the technological cost or the performance parameters that depend mostly on the elements of the cutting conditions.

In the analysis of machinability, one always begins with the simple (specific) determination and moves on to the complex (overall) determination. The simple determination of machinability establishes the influence of one factor only over one parameter, and the complex definition studies three factors together. The results of determination are classified in specialized reference directories or on software products [2].

Machinability of metals characterizes the internal conditions and external factors for utilizing the cutting ability of the tool. Machinability of the metal and the cutting ability of the instrument are two sides of the same problem. They exist objectively and are interrelated. These can be identified by the same experimental methods; they depend on the same factors and are evaluated quantitatively by almost equally selected parameters. They are basically studied for the ability of the processed metal to wear out the cutting tool and at the 
same time for the ability of the tool to resist this wear. In research and evaluation of the machinability of metal, it is assumed that the cutting ability of the instrument is a constant and vice-versa - in research and evaluation of the cutting ability; it is assumed that machinability is a constant. Most often, the object of study is machinability.

Machinability of metals and the cutting ability of tools are respectively functional and verified characteristics, because these can only be determined during or after a cutting process.

In general, the parameters of machinability characterize the reliability, the power factor and the economy of the cutting process. The reliability of the cutting process characterizes the ability of the technological system to preserve sustainable work piece formation and to perform its functions in relation to selected parameters - surface roughness (Ra), effective chip breaking $(\mathrm{CH})$ and life durability of the tool $(\mathrm{T})$, at the required level or at some predetermined defined interval [2]. The power of the cutting process includes the forces Fc, Ff, Fp, the moment Mc and the cutting power of Pc [8]. The economy of the cutting process is estimated with the cost $\mathrm{K}$ or the productivity $\mathrm{Q}$ parameters, which have particular relevance to practice [1].

Machining by chip removal accounts for both the physics of chip formation and as well as for the technological nature of the performed process of machining. The characteristics properties of machinability are complexity, intricacy, relativity and randomness.

Complexity. Machinability depends on many direct or indirect, controllable or uncontrollable factors such as the properties of the machined material, the characteristics of the cutting tool and the working conditions. It is assessed by type and content using multiple different technological or economic parameters.

Intricacy. It expresses the complex interaction between the machined metal and the cutter in the cutting process. Furthermore, the machinability factors act in different combination where the parameters of machinability alter in the course of the process of cutting.

Relativity. It expresses the fact that a certain metal under given set operating conditions, and using choosen cutting tool has one machining ability, and under other working conditions or using another cutting tool, machinability is different than the first.

Randomness. Under certain operating conditions ([vc, f, a]=const), the life of the cutting tool $T$ is a random variable, subject to the normal law of distribution $N\left(T_{m}, \sigma_{T}^{2}\right)$. The principle life duration dependence of $T-v_{c}$, as shown in Fig. 1, indicates a change in the life duration (Ta - average value, $T_{u}=T_{a}+3 \sigma_{T}$ - upper value and $T_{l}=T_{a}-3 \sigma_{T}-$ lower value) and in the respective cutting speeds. $\left(v_{c a}, v_{c l}, v_{c u}\right)$.
Likewise, the life dependence $T-f$ also determines

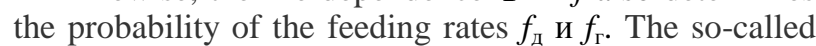
probability field of cutting conditions (Fig. 2) is constructed based on the probable settings of the cutting speeds. This is a new approach for determining the mode of cutting and is an alternative to the current deterministic approach. These directions of change in the details of the cutting conditions indicate the practical application of issues of machinability and the requirements for "improving" machining.

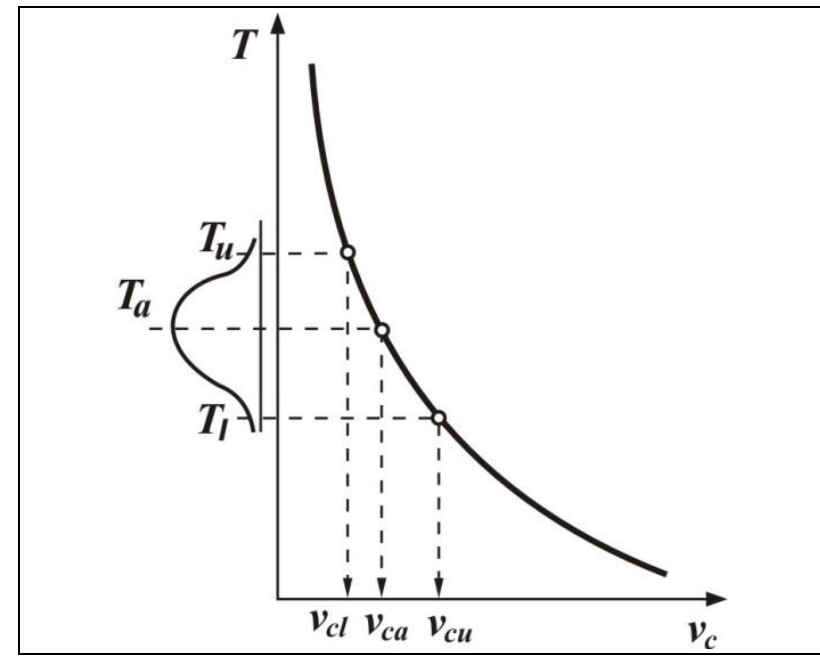

Fig. 1. Life dependence $T-\mathrm{v}_{\mathrm{c}}$ for probability approach

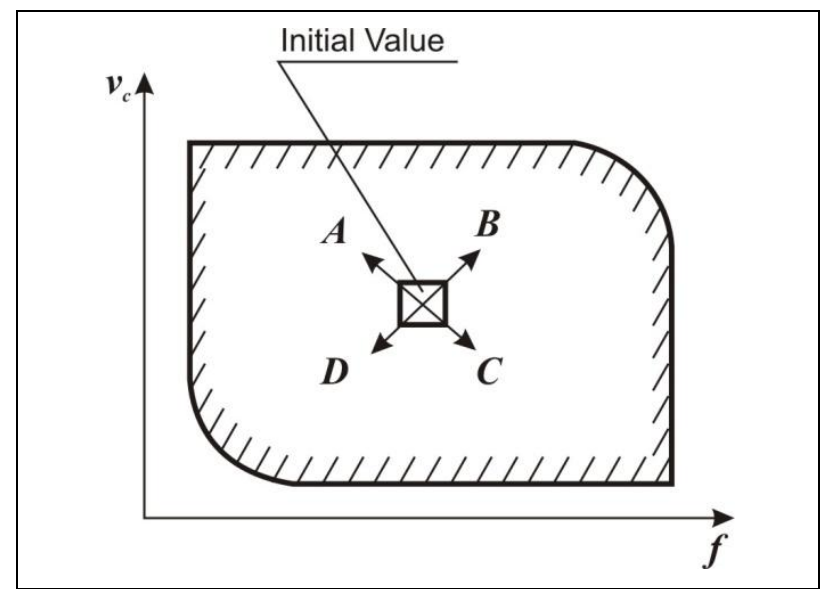

Fig. 2. Probability field

Initial Value:

A enhances roughness

B enhances chip breaking

$\mathrm{C}$ removes flutters

D prolongs life duration

\section{MACHINABILITY TRENDS}

There are two tendencies in considering machinability issues:

1. An integral and approximately permanent feature (material constant) of the metal, which trend is a pinned trend in Europe;

2. A technological characteristics of the metal and starting point for determining the cutting conditions, which trend is advocated in the U.S. and Japan. 
Machinability in both trends is seen in parallel with strive to establish and effectively use new machinable and cutting materials.

The achievements in analyzing and assessing machinability are currently limited to:

1. Significant reduction in loss of time, metal and money by statistical planning of experiments.

2. The use of the correlative - regressive analysis

3. Implementation of a more reliable and more promising probabilistic approach.

Despite the undeniable achievements in these trends, many methodical and practical issues of machinability still stand to be resolved. The trend of machinability can be expressed with the following few questions.

1. Is it possible to have a single, common enough and at the same time universal quantification of machinability?

2. Is it a real willingness to create and use a complex parameter (criterion), combining several technological, economical and physical parameters?

3. How can a cause and effect relationship be established by combining physical phenomena in the process of cutting with the technological parameters of machinability?

4. What are the advantages and disadvantages of regarding machinability as a material constant or as a technological feature?

Addressing these and other similar questions about machinability stand in the basis when designing and implementing an effective cutting process. The main goal of researchers in the future is to discuss these issues and the means of resolving them.

\section{METHODS OF DETERMINATION}

The experimental methods are divided into classical and quick (accelerated).

With classical (standard) methods, the extent of tool wear is monitored until it reaches the adopted wear criteria of $V B_{k}$ and the respective life durability is found by experimenting with different cutting speeds $v_{c}$ to obtain the dependence $T-v_{c}$ or experimenting with different items $\left(v_{c}, f, a\right)$ to obtain a common dependence.

With accelerated (express) methods, the actual cutting process is intensified one way or another, which shortens the investigation procedure. It is necessary, when using such method, to have a theoretical justification of phenomena, statistical analysis of the results and experimental verification of authenticity. An accelerated method can be put into practice when deviations from the results of the normal method are reasonably small or the value and direction of deviation are known. There is still no contemporary profound analysis of the causes of the low reliability of the results in the accelerated methods [7].

Methods for quick determination of the $T-v_{c}$ dependence have been sought for ever since Taylor. Comparing the results of accelerated tests with those of the normal tests, carried out by different authors, provided encouraging tendencies for use. On the other hand, quite widespread opinion is encountered that these methods with their little credibility are unable to replace the normal method. However, there is no deeper analysis of the reasons for poor reliability of the accelerated methods, despite the many attempts in this direction.

All known accelerated methods can be classified according to the method of extrapolation of the results of the $T-v_{c}$ life durability dependence. Reduction in the cutting time in order to obtain the dependence $T-v_{c}$, can be achieved in two ways.

The first way is when using higher cutting speeds than those used in industrial practice. Lower life durability values correspond to these speeds and the results from these tests meet the "lower" section of Taylor's straight line in the coordinate system $\ln T-\ln v_{c}$ - For the cutting speeds practically used, the life dependence $\ln T-\ln v_{c}$ is extrapolated from the results of the "lower" section.

The second way is when the measured tool wear is extrapolated to the criterion of wear $V B_{k}$. The corresponding dependence $T-v_{c}$ is obtained by extrapolating the constants $C_{T}$ or $C_{v}$.

The easiest and also the oldest way of shortening research time is to use continuous high-speed cutting. For the first time this method was used by Taylor in 1907, who adopted as a parameter (index) a cutting speed corresponding to a life duration of $20 \mathrm{~min}$.

The most popular and widely used are the accelerated methods based on linear growth in the time of cutting speeds. Cutting in this case is theoretically equivalent to cutting at constant rate, called equivalent speed.

All accelerated methods based on linear acceleration of speed are a logical extension of the 1935 method of Brandsman. He used a face-turning wheel from the centre to the periphery and the diameter, where the maximum tool wear occurs, was adopted as criterion. In 1936, Van Dong and Stegve [10] were the first to use face turning to obtain the dependence $T-v_{c}$ from two tests carried out at two wheel speeds.

In 1937, Krause and Wedel further elaborated the method with a larger number of tests and achieved a more reliable method. In 1938, Klushin perfected the method of face turning using several strokes with a turning wheel of a smaller diameter. In 1943, Feldstein [6] theoretically justified the dependence "rotation frequency - radius, where wear has occurred". He displayed the relationship which transforms the magnitudes $n_{T}$ and $C_{T}$ in Taylor's equation. The linear dependence $\ln n$ - $\ln R$ can be obtained after substituting the cutting time and the cutting speed in Taylor's equation, where $R$ is the radius at which the maximum wear of the tool occurs.

In 1961, Jansen proposed and theoretically justified a method in cylindrical turning with the rotation speeds of 
the machine constantly increasing in time. In 1966, Hegibotem and Pandeya [3] proposed a method for rapid determination of machinability by turning a conical surface, i.e. linear increase of cutting speed. The authors assumed the existence of proportionality between the time of work and tool wear.

In 1968, Andonov [2] proposed a rapid method for determining machinability by way of intermittent (discrete) increment of the cutting speeds in time. The essence of the method consists of longitudinal turning over a cylindrical workpiece, distributed onto multiple sectors (orifices) of equal length $l_{o}$ and diameter $\mathrm{D}$. The first test was conducted at the first orifice at the speed of $n_{1}$, then the second at $n_{2}=n_{1} \varphi$, the third at $n_{3}=n_{1} \varphi^{2}$, etc., where $\varphi$ is the index of the geometrical series of rotation speeds (e.g. $\varphi=1,26$ ). This methodology can also be applied to the processes of drilling, core drilling, reaming, slabbing and face milling.

\section{PRACTICAL APPLICATION}

The starting point is the extended Taylor formula $v_{c}=f(T, f, a)$. The cutting speed $v_{c}$ is determined according to present constant tool life durability and selected, by technological considerations, a and f factors. This relationship is called the characteristic dependence (line) Fig.3. The analytical form of the characteristic line has the form of $v_{c}=\frac{K}{f^{y_{v}}}$, where $K=\frac{C_{V}}{T^{m} a^{x_{v}}}$ is the technological constant, in which the values $C_{v}, m$ and $x_{v}$ depend on the type and properties of the machined metal and the cutting tool.

The position of the characteristic line depends on the size of the constant $K$ and type - on the size of the degree indicator $y_{v}$. By increasing the life durability of the tool $T$ and the cutting depth a, the characteristic line shifts down, but not in proportion to their alterations Fig.4.

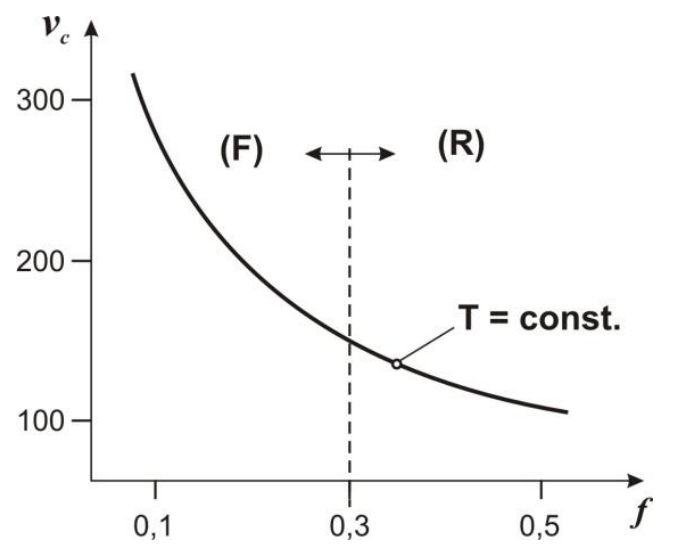

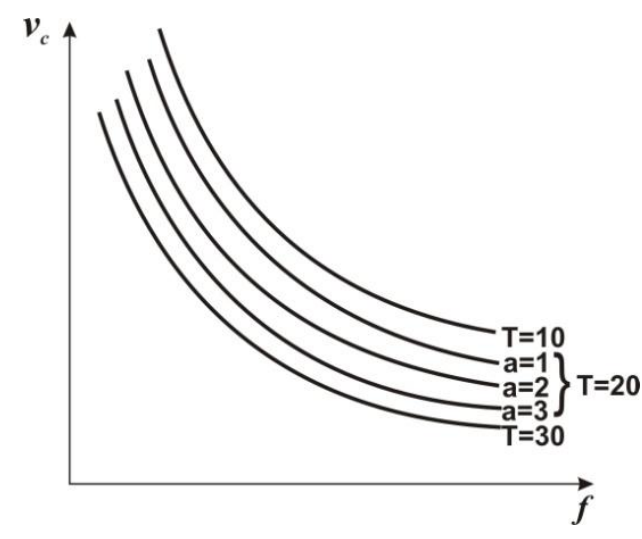

Fig.4. Characteristic dependence $\mathrm{v}_{\mathrm{c}}-\mathrm{f}$

Fig. 3 shows a principal characteristic line in which the fields of pure and rough machining processes are marked with $(\mathrm{P})$ and $(\mathrm{R})$. The characteristic relationships in the double logarithmic coordinates $\ln v_{c}-\ln f$ are straight lines with a negative angular coefficient.

\section{CONCLUSION}

The characteristic lines under the same conditions and for the same machined metal are equidistant and for the different machined metals they are of different inclination. Since the method is determined, the positions of the characteristic lines are constant and the cutting speed has a precisely determined value.

\section{REFERENCES}

[1] Andonov, I., Modeliranje na procesa na rezanie, , Modelling of the cutting process , Teniceski Universitet, Sofia, 1997 g., 154, (monografija)

[2] Andonov, I.,Obrabotvaemost, Workability, Avangard Prima, Sofia, 2011, (monografija)

[3] Armarego, I. D. A., I. Braun, Obrabotka metallov rezaniem, Processing of metal cutting M., Mashinostroenie, 1977, 225

[4] Misheleti, Zh. F., Issledovanie Obrabotyvaemosti metallov rezaniem, E. I. Rezhushchie instrument, Investigation of the machinability of metal cutting, Cutting tools, 41, 1970, 1-18

[5] Zorev, N. N., kolektiv avtorev, Sbornik "Razvitie nauki o rezanii metallov", The development of the science of metal cutting, M., Mashinostroenie, 1967

[6] Feldstein, E. I., M., Mashgiz, Obrabotyvaemost stali, The machinability of steel, 1953

[7] Andonov, I., Analyzing the properties and ways for assessment of the machinalibity, Journal of Materials Science and Technology, Bulgarian Academy of Sciences, Sofija, Vol.5, 1997, 1, 42-48.

[8] Andonov, I., N. Qehaja., Modeling the cutting forces in turning, Bultrib, Sofia , 2006, 30-40

[9] Boothroyd, G., W. A. Knight., Fundamentals of Machining and Machine Tools, Third Edition, CRC Press, 2006, 573

[10] Van Dongen J. R. J., Ermittlung der zuläsigen Schnittgeschwindigkeit aus Plandrehversuchen Stahl und Eisen Determining the allowable cutting speed of steel and iron facing trials 1936 t. 56, № 39, 1185-1187 